\title{
A membrane protein/signaling protein interaction network for Arabidopsis version AMPv2
}

\section{Sylvie Lalonde ${ }^{1 *}$, Antoinette Sero ${ }^{1}$, Réjane Pratelli ${ }^{1+}$, Guillaume Pilot ${ }^{1+}$, Jin Chen ${ }^{1+}$, Maria I. Sardi ${ }^{1}$, Saman A. Parsa' , Do-Young Kim ${ }^{1}$, Biswa R. Acharya ${ }^{2}$, Erica V. Stein ${ }^{3}$, Heng-Chen Hu ${ }^{4}$, Florent Villiers ${ }^{4}$, Kouji Takeda ${ }^{4}$, Yingzhen Yang ${ }^{3}$, Yong S. Han ${ }^{4}$, Rainer Schwacke ${ }^{5}$, William Chiang ${ }^{6}$, Naohiro Kato $^{6}$, Dominique Loqué$^{7}$, Sarah M. Assmann $^{2}$, June M. Kwak ${ }^{4}$, Julian I. Schroeder ${ }^{3}$, Seung Y. Rhee ${ }^{1}$ and Wolf B. Frommer ${ }^{1}$}

\author{
1 Department of Plant Biology, Carnegie Institution for Science, Stanford, CA, USA \\ 2 Department of Biology, Pennsylvania State University, University Park, PA, USA \\ ${ }^{3}$ Division of Biological Sciences, Cell and Developmental Biology, University of California, San Diego, La Jolla, CA, USA \\ 4 Department of Cell Biology and Molecular Genetics, University of Maryland, College Park, MD, USA \\ ${ }_{5}$ Botanisches Institut der Universität zu Köln, Köln, Germany \\ ${ }^{6}$ Department of Biological Sciences, Louisiana State University, Baton Rouge, LA, USA \\ Feedstocks, Joint BioEnergy Institute, Emeryville, CA, USA
}

\section{Edited by:}

Steven Huber, University of Illinois at Urbana-Champaign, USA

Reviewed by:

Jeffrey F. Harper, University of Nevada, Reno, USA

Ján A. Miernyk, University of Missouri, USA

Waltraud Schulze, Max Planck Institute for Plant Physiology, Germany

*Correspondence:

Sylvie Lalonde, Carnegie Institution for Science, 260 Panama St., Stanford, CA 94305, USA.

e-mail: slalonde@stanford.edu

\section{${ }^{+}$Present address:}

Réjane Pratelli and Guillaume Pilot, Department of Plant Pathology, Physiology and Weed Science, Virginia Tech, VA 24061, USA; Jin Chen, MSU-DOE Plant Research Lab and Department of Computer Science and Engineering, Michigan State University, MI 48824, USA
Interactions between membrane proteins and the soluble fraction are essential for signal transduction and for regulating nutrient transport. To gain insights into the membrane-based interactome, 3,852 open reading frames (ORFs) out of a target list of 8,383 representing membrane and signaling proteins from Arabidopsis thaliana were cloned into a Gatewaycompatible vector. The mating-based split ubiquitin system was used to screen for potential protein-protein interactions (pPPIs) among 490 Arabidopsis ORFs. A binary robotic screen between 142 receptor-like kinases (RLKs), 72 transporters, 57 soluble protein kinases and phosphatases, 40 glycosyltransferases, 95 proteins of various functions, and 89 proteins with unknown function detected 387 out of 90,370 possible PPIs. A secondary screen confirmed 343 (of 386) pPPIs between 179 proteins, yielding a scale-free network $\left(r^{2}=0.863\right)$. Eighty of 142 transmembrane RLKs tested positive, identifying 3 homomers, 63 heteromers, and 80 pPPIs with other proteins. Thirty-one out of 142 RLK interactors (including RLKs) had previously been found to be phosphorylated; thus interactors may be substrates for respective RLKs. None of the pPPIs described here had been reported in the major interactome databases, including potential interactors of G-protein-coupled receptors, phospholipase C, and AMT ammonium transporters. Two RLKs found as putative interactors of AMT1;1 were independently confirmed using a split luciferase assay in Arabidopsis protoplasts. These RLKs may be involved in ammonium-dependent phosphorylation of the $\mathrm{C}$-terminus and regulation of ammonium uptake activity. The robotic screening method established here will enable a systematic analysis of membrane protein interactions in fungi, plants and metazoa.

Keywords: protein interaction, transport, split ubiquitin system, yeast two hybrid, receptor, kinase, phosphorylation

\section{INTRODUCTION}

Membrane proteins play crucial roles in many biological processes. They control the cell's permeability to a myriad of compounds, mediate uptake and release of ions, metabolites and proteins across subcellular membranes, are involved in vesicle fusion, and are responsible for sensing chemical and physical stimuli from the environment (nutrients, hormones, light, $\mathrm{pH}$, etc.).

Both regulation of transport activity and communication involve interactions of membrane proteins either with each other or with proteins in the adjacent soluble compartments. The development and use of a wide spectrum of new tools for testing protein-protein interactions has been key to much of the progress in understanding cellular functions. Despite the importance, we know only a fraction of the total interactome, and our knowledge is specifically limited in the case of membrane proteins. Large-scale protein interaction screens in yeast or animal systems, which in part made use of the classical yeast two hybrid $(\mathrm{Y} 2 \mathrm{H})$ system, have provided at least a partial overview over the potential interactome in these organisms (Rual et al., 2005; Yu et al., 2008; Simonis et al., 2009). The pioneering work of Vidal's group has provided most of the interactome data so far. At present, the human interactome comprises $\sim 130,000$ binary interactions, with most of the interactome still remaining to be identified (Venkatesan et al., 2009). A bona fide plant interactome is still outstanding; therefore, systems approaches have to rely mainly on data for interactions of homologs from other organisms (GeislerLee et al., 2007). Particularly, knowledge of the membrane protein interactome is limited in all organisms, because conventional high throughput $\mathrm{Y} 2 \mathrm{H}$ assays are not designed to detect potential proteinprotein interactions (pPPIs) of membrane proteins.

To gain insights into the membrane-based interactome, the mating-based split ubiquitin system (mbSUS) was developed, which specifically detect interactions of membrane proteins and of membrane 
proteins with signaling proteins (Obrdlik et al., 2004; Miller et al., 2005). The split ubiquitin system concept relies on sequestration of a transcription factor to the membrane and its subsequent release when two proteins interact. It is based on peptide complementation and uses a split ubiquitin. The N-terminal domain of ubiquitin (Nub) when co-expressed with its C-terminal half (Cub) reconstitutes functional ubiquitin (Johnsson and Varshavsky, 1994). A Nub mutant, NubG (containing mutation Ile13Gly) with reduced affinity (compared to wild-type Nub) to the Cub moiety is unable to reconstitute functional ubiquitin unless brought into the vicinity of the Cub domain via interaction of two fusion partners (Johnsson and Varshavsky, 1994). An artificial transcription factor, PLV (protease A - LexA - VP16), is fused in frame to the C-terminal Cub moiety. When two proteins interact, the NubG and Cub moieties form a functional ubiquitin, and endogenous ubiquitin-specific proteases release the transcription factor into the cytosol. The transcription factor diffuses into the nucleus where it activates the transcription of the reporter genes (His3, Ade2, and LacZ). The split ubiquitin system was further improved for high throughput screens by introducing a mating approach (mbSUS) (Obrdlik et al., 2004). Subsequently, mbSUS was further modified to incorporate the Gateway recombination system for simplified cloning.

The split ubiquitin system has successfully been used to analyze pPPIs among 705 proteins annotated as integral to a cellular membrane in yeast (Miller et al., 2005). The screen identified 1,985 putative interactions among 536 proteins. Recently, a plant split ubiquitin system was developed and used to test interactions of translocon complex at the outer chloroplast membrane (Rahim et al., 2009). The split ubiquitin system identified the potential for oligomerization of plant transporters such as potassium channels, ammonium transporters, calcium/proton antiporters, $\mathrm{H}^{+}$sucrose cotransporters, and a mammalian phosphate transporter (Schulze et al., 2003; Obrdlik et al., 2004; Gisler et al., 2008; Zhao et al., 2009). The identification of AMT oligomerization was a key step toward the characterization of the novel allosteric regulation of AMT activity by the C-terminus of neighboring subunits in a trimeric complex (Loqué et al., 2007). Extracellular ammonium was found to trigger phosphorylation of a specific threonine (T460) in the C-terminus of AMT1;1 (Lanquar et al., 2009). Additional phosphorylated sites were found in the C-terminus using phosphoproteomic studies (Lanquar et al., 2009). The split ubiquitin system may thus allow us to identify the respective protein kinases (Lanquar and Frommer, 2010). The split ubiquitin system was also successful in identifying a physical interaction between the dopamine transporter and the synaptic vesicle protein synaptogyrin-3 (Egana et al., 2009), as well as interactions between five different mammalian transporters and PDZ domain-containing partners (Gisler et al., 2008). Harter's group used mbSUS to show that ethylene receptors form homomeric and heteromeric protein complexes (Grefen et al., 2008). Similarly, an interactions between cytosolic glutamine synthetase of soybean root nodules and the aquaglyceroporin nodulin-26 was identified (Masalkar et al., 2010). In most of these examples, data obtained with the split ubiquitin system were confirmed independently by a variety of orthogonal interaction methods, supporting the reliability of this assay system.

The goal of the work presented here was to lay the foundation for a systematic screen of the Arabidopsis membrane protein interactome and its interface with key signaling proteins. After establishing a target list of genes, the first step was to clone the open reading frames (ORFs) from Arabidopsis thaliana. A Gateway-based strategy was used to create 3,852 Entry clones that were then mobilized into the mbSUS destination vectors. After yeast transformation, the Cub fusions were tested for "false positive" and "false negative" read-out. A pilot screen (AMPv1, Associome of membrane proteins version 1; Chen et al., personal communication) suggested that interaction tests in 96-well would not provide sufficient throughput for a systematic analysis of membrane signaling protein interactions from Arabidopsis. Here, each Cub clone was then mated against a Nubfusion collection in a 384-well format and tested for interactions in a 1536-well format. In this screen (AMPv2), we tested 90,370 potential interactors and found 343 pPPIs between 179 proteins. Interactions between the ammonium transporter AMT1;1 and two receptor-like kinases (RLKs) identified in the screen were independently confirmed using a split luciferase assay.

\section{MATERIALS AND METHODS ARABIDOPSIS FIRST-STRAND CDNA SYNTHESIS}

RNA was extracted from Arabidopsis seedlings and flowers as described by Downing et al. (1992). DNA was removed by DNaseI treatment (Invitrogen) followed by ethanol precipitation. The polyA+ fraction was purified using DynaBeads Oligo(dT) (Invitrogen) and cDNA was synthesized using the SuperScript III kit (Invitrogen). mRNA for seedlings and flowers was isolated separately and mixed in a 1:1 ratio after the synthesis of the first-strand cDNA. The cloning scheme is illustrated in Figure 1.

\section{CLONING OF ARABIDOPSIS ORFs}

Primers for target genes were designed in bulk with a command-line version of Primer3 (Rozen and Skaletsky, 2000). ORFs (without stop codon) were amplified by PCR from Arabidopsis first-strand cDNA using KOD polymerase (Novagen). PCR products were isolated from crystal violet-stained (Rand, 1996) agarose gels using a NucleoSpin extraction kits (Macherey-Nagel). Purified PCR products were cloned into pDONR221 or pDONR221-f1 (f1 origin of replication was inserted counter-clockwise into the unique PciI restriction site after removing 5 '-overhangs with T4 DNA polymerase). Colony PCR was used to identify plasmids containing an insert with the expected size (low resolution separation on 96 sample gels). Cloning products were sequenced from both ends with a median read length of 570 Phrep20 bases into the gene (Beckman Coulter Genomics). Plasmids with the correct sequences, or clones that contained multiple silent mutations but no more than a single amino acid change were isolated, verified by restriction digest analysis (PvuII) and transferred into the mbSUS destination vectors by in vitro LR recombination. Clones received from third parties (including ABRC; Underwood et al., 2006; Popescu et al., 2009) were reconfirmed by restriction analysis and/or re-sequencing.

\section{CONSTRUCTION OF GATEWAY-COMPATIBLE mbSUS DESTINATION VECTORS}

The mbSUS interaction trap was originally created for cloning ORFs using in vivo recombination directly into the mbSUS vectors in yeast (Obrdlik et al., 2004). The vectors contained attB1 and attB2 site allowing for an easy transfer of the ORFs to other destination vectors. To increase the efficiency of cloning for this project, 


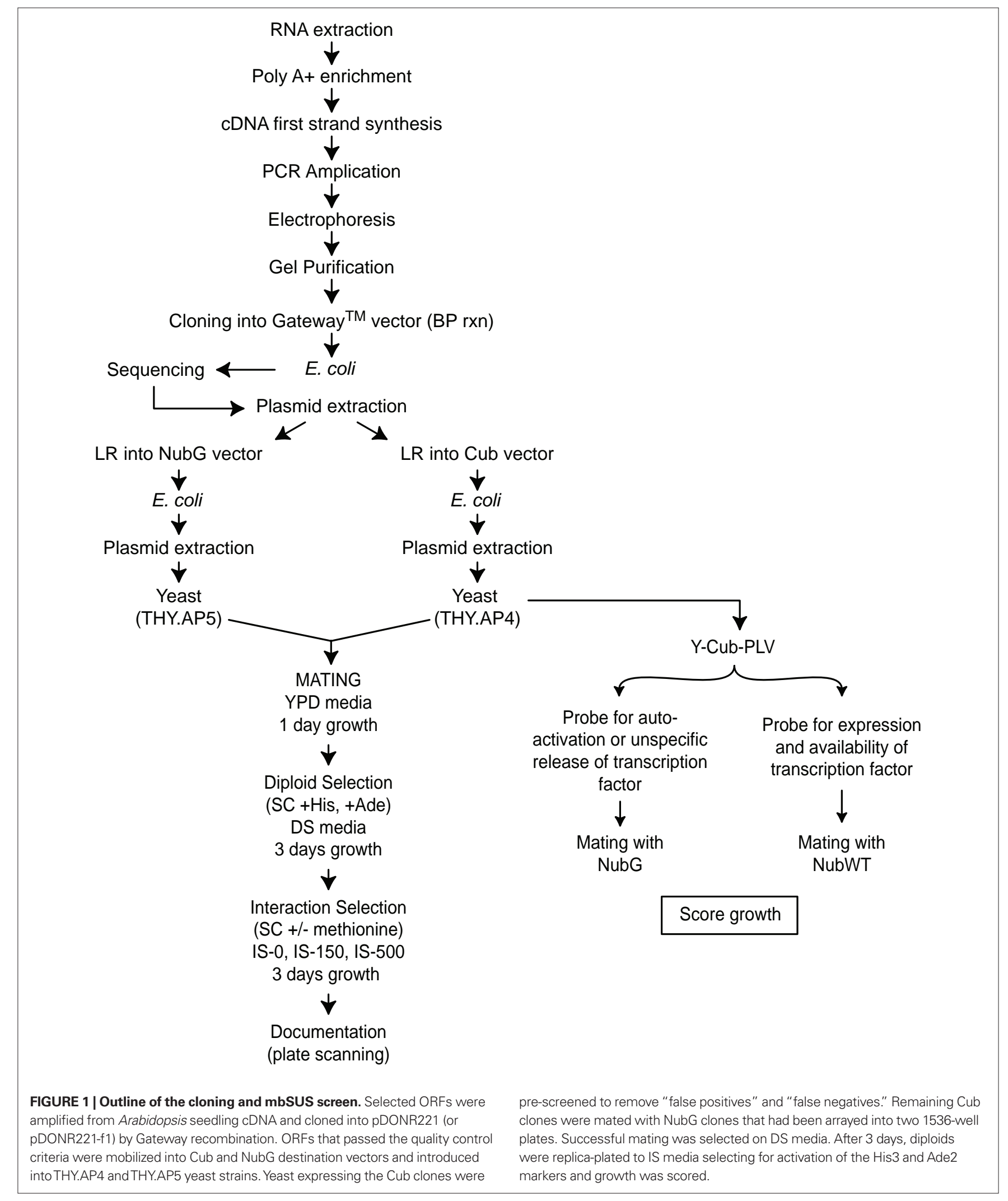

the KanMX containing vectors pXNgate22-HA and pMetYCgate (Obrdlik et al., 2004) were treated with BP clonase in the presence of pDONR221 to obtain mbSUS Gateway (GW) destination

vectors. Bacteria containing plasmids (with Gateway cassette, $c c d \mathrm{~B}$ and chloramphenicol resistance genes) were selected in $c c d \mathrm{~B}$ survival cells. The new mbSUS Gateway destination vectors were 
named pXN22_GW and pMetYC_GW, respectively. Identity of the plasmids was confirmed by sequencing the borders of the region of interest. Plasmids are available through $\mathrm{ABRC}^{1}$ and maps are available through the project's website ${ }^{2}$.

\section{YEAST TRANSFORMATION}

The yeast strains THY.AP4 [MATa ura3 leu2 lexA::lacZ::trp1 lexA::HIS3 lexA::ADE2] and THY.AP5 [MAT $\alpha$ URA3 leu2 trp1 his3 loxP::ade2] (both derived from CEN.PK113-17D [MAT $\alpha$ URA3 leu2 trp1 his3 ADE2]) were used in combination with pMetYC_ GW (Cub Gateway destination vector), and pXN22_GW (NubG Gateway destination vector) respectively (Obrdlik et al., 2004). Yeast strains were transformed with respective vectors using the LiAc method (Gietz and Woods, 2002) optimized for high throughput. Briefly, strains were inoculated in $15 \mathrm{ml}$ of YPD-adenine medium and diluted the following day to $\mathrm{OD}_{600} 0.1$ (final volume of $300 \mathrm{ml}$ ). Strains were incubated at $28^{\circ} \mathrm{C}$ until $\mathrm{OD}_{600} 0.5-0.6(\sim 6 \mathrm{~h})$. Cells were harvested by centrifugation and resuspended in $100 \mathrm{mM} \mathrm{LiAc}$ in Tris-EDTA (10 mM Tris, $1 \mathrm{mM} \mathrm{EDTA} \mathrm{pH} \mathrm{7.5).} \mathrm{The} \mathrm{original}$ $300 \mathrm{ml}$ of culture resulting in $1.8 \mathrm{ml} \mathrm{LiAc}$ solution was used for one 96-well plate. In a PCR microplate (E \& K Scientific), $1 \mu$ l plasmid DNA (50-100 ng/ $\mu \mathrm{l})$ was dispensed into each well of a 96-well microplate, $99 \mu \mathrm{l}$ of a master mix [7 $\mathrm{ml} 50 \%(\mathrm{w} / \mathrm{v})$ polyethylene glycol 4000 (Fluka \#81240), $0.8 \mathrm{ml} 1 \mathrm{M} \mathrm{LiAc}$ in TE, $1.8 \mathrm{ml}$ cells, $0.3 \mathrm{ml}$ freshly denatured ssDNA $(8-10 \mathrm{mg} / \mathrm{ml})]$ was added and incubated for $30 \mathrm{~min}$ at $28^{\circ} \mathrm{C}$, followed by a heat shock at $42^{\circ} \mathrm{C}$ for $13 \mathrm{~min}$. Cells were washed in water and resuspended in $75 \mu \mathrm{l}$ water. Ten microliters of cells were plated on solid N (THY.AP5) or C (THY.AP4) media using a Hydra96 (Art Robbins Instruments, Sunnyvale). After growth for 3 days, cells were transferred to liquid $\mathrm{N}$ and $\mathrm{C}$ media in 96-well plates, respectively. After 3 days of growth in liquid culture, glycerol stocks were prepared and cells were transferred back to solid $\mathrm{N}$ and $\mathrm{C}$ media for further analysis. Four hundred and ninety unique ORFs (Table S1 in Supplementary Material) were mobilized into the mbSUS destination vectors by Gateway LR in vitro recombination. Membrane-localized proteins with cytosolic C-termini were fused to Cub-PLV: 443 ORFs were mobilized into the NubG- and 204 in the Cub-vector.

\section{YEAST MEDIA}

YPD media, synthetic complete (SC) media, and drop-out (minus histidine, adenine, uracil, tryptophan, leucine, and methionine) media were prepared according to standard protocols (Adams et al., 1998). Depending on the selection, the SC media was supplemented with $20 \mathrm{mg} / \mathrm{L}$ adenine hemisulfate, $20 \mathrm{mg} / \mathrm{L}$ histidine- $\mathrm{HCl}, 500 \mu \mathrm{M}$ methionine, $20 \mathrm{mg} / \mathrm{L}$ tryptophan, $20 \mathrm{mg} / \mathrm{L}$ uracil, and/or $240 \mathrm{mg} / \mathrm{L}$ leucine. Cells harboring the Cub plasmids were grown on SC supplemented with tryptophan, histidine, adenine, and uracil (C media) and cells with the NubG plasmid on SC with leucine, adenine, and histidine (N media). Diploid cells were selected on SC media supplemented with adenine and histidine (DS media), while selection for pPPIs was performed on SC supplemented with 150 or $500 \mu \mathrm{M}$ methionine (IS-150 and IS-500 media) or without methionine (IS-0 media). Cub

'http://abrc.osu.edu/

${ }^{2} \mathrm{http}: / /$ associomics.org fusions are under the control of the methionine repressible MET25 promoter; increasing the amount of methionine in the media decreases the expression level and hence, increases the stringency.

\section{IDENTIFICATION OF "FALSE POSITIVE" AND "FALSE NEGATIVE" CANDIDATES}

Cub clones were pre-screened to identify "false positive" and "false negative" candidates (Figure 1). Cub clones in THY.AP4 were arrayed on C media in 384-well format using the RoToR HDA yeast pinning robot (Singer Instruments, UK). Recombinant THY. AP4 cells were mated with a yeast strain (THY.AP5) expressing either soluble NubWT (control for "false negatives") or soluble NubG alone (control for "false positives") on N media. Cells were allowed to mate on YPD media for $24 \mathrm{~h}$ at $28^{\circ} \mathrm{C}$ and then replicaplated onto DS media. Interactions were selected on IS-0, IS-150, and IS-500 media. Growth was documented by scanning plates on a flatbed scanner (CanoScan 8400F, Canon). Only Cub fusions showing no growth when mated with a strain containing soluble NubG (Cub-fusion that do not autoactivate the reporters) and growth for soluble NubWT (indicating protein expression) were used for the interaction screen.

\section{ROBOTICS}

NubG clones were re-arrayed in 384-well format (RoToR HDA pinning robot, Singer Instruments, UK) and were mated with individual Cubs. For this purpose, individual Cub clones were grown in $15 \mathrm{ml} \mathrm{C}$ media, distributed into a 96-well plate and arrayed from liquid media onto solid C media in 384-well format. Plates containing cells with Nub and Cub clones were mated (see above). After $24 \mathrm{~h}$ at $28^{\circ} \mathrm{C}$, cells were plated on DS media to select for diploid cells and grown for 3 days at $28^{\circ} \mathrm{C}$. Cells were re-pinned in 1536-well format on IS media containing 0,150 , or $500 \mu \mathrm{M}$ methionine for selection of pPPIs (IS-0, IS-150, and IS-500, respectively). Positive spots were scored. To independently verify the pPPIs, the original clones identified as part of the PPPI network were re-arrayed in 96-well format using a BioRobot 3000 (Qiagen) and tested for His3, Ade2, and the third marker LacZ.

\section{$\beta$-GALACTOSIDASE ASSAY}

The $\beta$-galactosidase assay, which tests for the third mbSUS marker lacZ, was performed with cells grown on a nitrocelluloseoverlaid plate over an IS media plate (IS-0, IS-150, and IS-500). The $\beta$-galactosidase assay was performed as described (Obrdlik et al., 2004). The nitrocellulose filters were scanned on a flatbed scanner (CanoScan 8400F, Canon) and the intensity of the spots was quantified using GenePix v6.1 software (Molecular Devices, Sunnyvale) after conversion of the images to black and white. For each treatment (IS-0, IS-150, and IS-500 media), the average intensity and standard deviation were calculated; the cut-off value was set to the average minus one standard deviation. For a given pair, an intensity value higher than the cut-off for at least one treatment was considered a pPPI for the final network. The resulting network was named AMPv2 and can be queried through the project website ${ }^{3}$.

${ }^{3}$ http://associomics.org/search.php 


\section{SPLIT LUCIFERASE INTERACTION ASSAY}

Selected pPPIs were tested in Arabidopsis protoplasts using the orthogonal Renilla luciferase complementation assay (Fujikawa and Kato, 2007; Kato et al., 2010). SYP122 (AT3G52400)/VAMP721 (AT1G04750), and SYP122/PHT4 (AT2G38940) pairs were used as a positive and negative controls, respectively (Fujikawa and Kato, 2007). Arabidopsis protoplasts were isolated from leaves of 4-week-old plants according to Kato and Jonse (2010). Renilla luciferase activity (split luciferase assay) was measured in 96-well white plate using the ViviRen substrate according to Kato and Jonse (2010) using a microplate luminometer (Promega).

\section{RESULTS}

\section{THE TARGET GENE LIST}

To select proteins for the membrane protein/signaling protein interaction screen, 26,922 protein sequences from Arabidopsis (assembly TAIR 7) were grouped into protein families using the Markov Cluster (MCL) algorithm ${ }^{4}$ (Enright et al., 2002) based on pre-computed sequence similarity information. A total of 3,360 clusters containing 21,807 proteins, as well as 5,115 singletons were identified. The composition of each cluster was analyzed using multiple sequence alignments. Proteins that aligned only partially (less than $\sim 75 \%$ ) with other proteins of a cluster were removed to ensure that each cluster contained proteins of one family. Clusters of interest were selected based on locus descriptions from TAIR, published data, and topology as predicted by the Aramemnon database (Schwacke et al., 2003) to select (1) plasma membrane proteins, and (2) proteins involved in signaling and in protein turnover. Certain classes of soluble proteins not involved in membrane signal transduction or ubiquitination were excluded, including transcription factors (families retrieved from TAIR), pentatricopeptide domaincontaining proteins, plastidial and mitochondrial proteins. Eight hundred and forty-six clones were obtained from third parties involved in various processes ( 310 were included in the present screen) were included. In addition, 209 proteins that had been previously shown to localize to membranes by proteomic or cell biological approaches were added to the target list.

Protein topologies were assigned using published data and similarities to known proteins, or the number and orientation of transmembrane spans was predicted using Topcons (Bernsel et al., 2009), TMHMM (Krogh et al., 2001), and Phobius (Kall et al., 2007). Proteins predicted to have both $\mathrm{N}$ - and C-terminus outside the cytosol were eliminated leading to a final list of 8,383 candidates. This list contains 4,332 proteins with $\geq 1$ transmembrane domains and are thus suitable as Nub and Cub fusions. Four hundred and thirty-two proteins were predicted to be myristoylated and can also be used as Nub and Cub fusions, while 4,051 soluble proteins were tested only as Nub fusions.

\section{CLONING OF ARABIDOPSIS ORFS FOR THE mbSUS SCREEN}

The target list was used as the basis to clone a maximal number of ORFs. For cloning, RT-PCR was performed on Arabidopsis thaliana Col-0 cDNA from seedlings and flowers. A variety of Gateway ${ }^{\mathrm{TM}}$ cloning strategies was used with different success rates. Initially, ORFs were cloned using the $\mathrm{TOPO}^{\circ} \mathrm{TA}$ system in $\mathrm{pCR} 8$ vector

${ }^{4} \mathrm{http}: / /$ micans.org/mcl
(Invitrogen). However, the non-directional approach required additional analyses to identify clones suitable for screening. Cloning into pENTR-D (Invitrogen; directional cloning kit) did not yield a prevalence of correctly oriented clones; furthermore, unexpected $13 \mathrm{bp}$ insertions at the $5^{\prime}$-end led to frame shifts. By comparison, in vitro recombination using BP cloning (Gateway, Invitrogen) was efficient. For Gateway cloning, primers with attB1 and attB2 sites were designed. Resulting clones were tested for correct insert size by restriction digests and sequenced from both ends. Clones selected for further processing were allowed to contain multiple silent mutations but no more than a single amino acid change. Based on these quality control ( $\mathrm{QC})$ criteria (size and sequence), the overall cloning success was $\sim 48 \%$. For clones that passed QC, the error rate was $0.028 \%$, or one error per 3,624 bases (292 errors in 1,924 clones). To date, 3,852 Entry clones (representing 3,571 unique AGIs) have been generated (846 genes as thirty party donations) and 2,106 ORFs have been made available through $\mathrm{ABRC}^{5}$ (cf. Table $\mathbf{S 2}$ in Supplementary Material). A set of Gateway-compatible mbSUS destination vectors was constructed, and the first 490 genes were mobilized into pMetYC_GW (204 Cub clones) and pNX22_GW destination vectors (443 Nub clones; Overlap: 157 ORFs present in both Nub and Cub vectors); this pilot study reports potential protein-protein interactions corresponding to a set of 490 proteins.

\section{IDENTIFICATION OF "FALSE POSITIVES/NEGATIVE" CANDIDATES}

A pre-screen was performed to identify potential Cub fusions producing "false negative" and "false positive" reports. Correctly folded and efficiently expressed Cub fusions are expected to induce reporter activity when mated with cells expressing the soluble wildtype version of Nub (NubWT), which has a strong affinity for the Cub domain, (note that mbSUS uses a mutant NubG with reduced affinity for Cub; Johnsson and Varshavsky, 1994). Sources of potential "false negative" interactions include: gene products that expose the Cub-PLV domain to an intracellular compartment such as ER or Golgi and thus do not produce an interaction in the cytosol, or proteins in which the Cub-PLV domain is not folded properly and thus cannot be recognized by ubiquitin-specific proteases. "False positives" were identified through interaction tests with soluble NubG, specifically gene products that activated the reporters in the absence of an interaction partner. The pre-screen lead to elimination of 69 out of 204 ORFs cloned in the Cub-vector, resulting in $135 \mathrm{Cub}$ clones for further analysis (Table S1 in Supplementary Material). The rate of clones eliminated in the pre-screen was slightly lower (66.2\% retained vs. $51.7 \%$ ) compared to the screen performed with endogenous yeast membrane proteins (Miller et al., 2005).

\section{ROBOTIC SCREEN FOR INTERACTIONS}

A robotic mating procedure was established in 384-well plates. Subsequently, interaction tests were performed in 1536-well format using a Singer RoToR HDA replica-plating robot. To establish the conditions for the high throughput screen, $443 \mathrm{NubG}$ fusions were first arrayed into 96-well format (seven plates), transferred into two 1536-well plates (in quadruplicate) and screened against the pre-screened $135 \mathrm{Cub}$ fusions. Mating reactions were performed by robotic pinning of individual Cub-strains onto the

${ }^{5}$ www.abrc.osu.org 


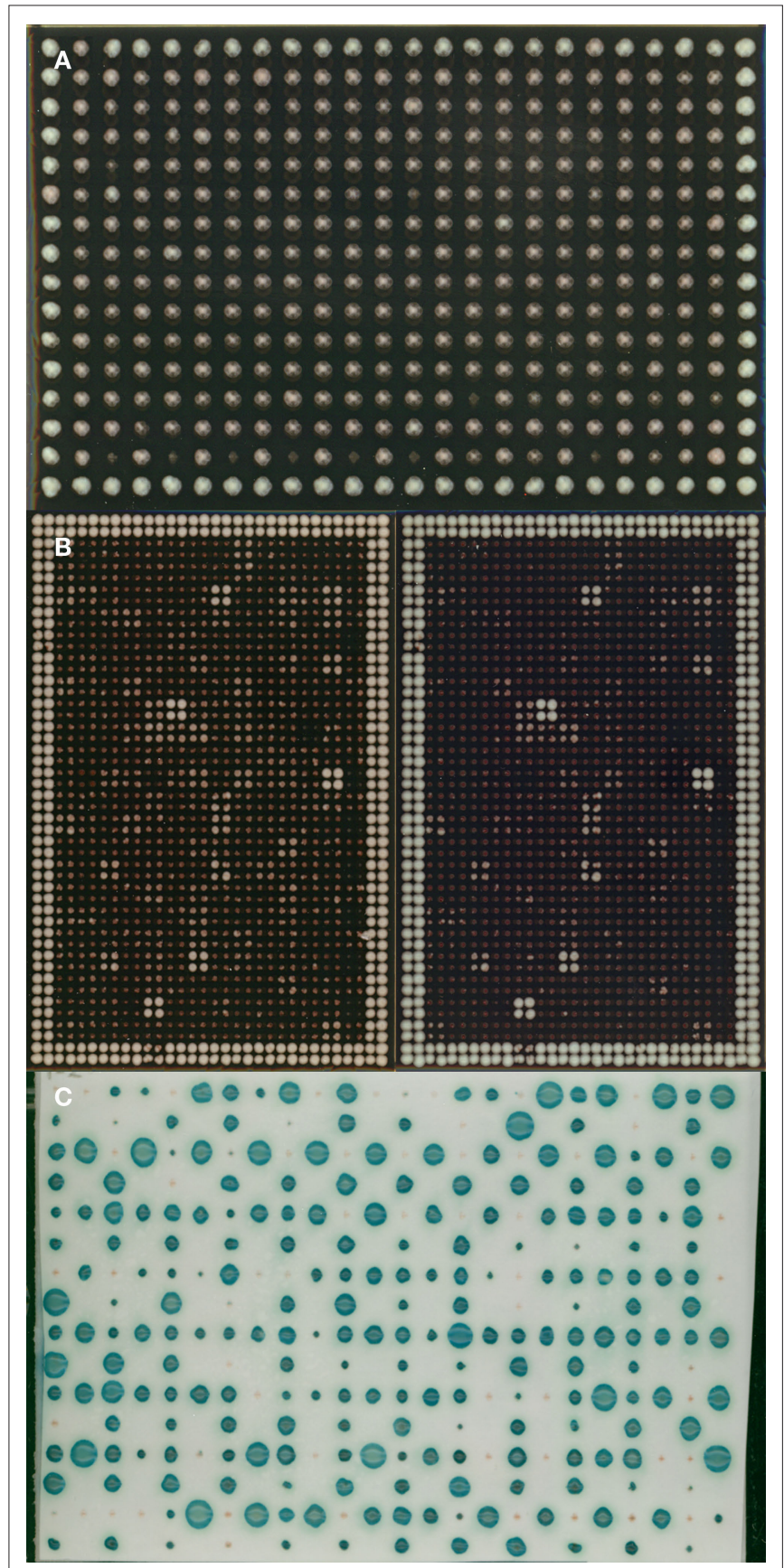

FIGURE 2 | pPPIs detected in the AMPv2 screen. (A) Selection of diploid cells on DS media supplemented with adenine and histidine. (B) Successful mating (His3, Ade2 positive) was selected on IS-0 media without met (right) and IS-500 with $500 \mu \mathrm{M}$ met (left). (C) Representative image of the $\beta$-galactosidase assay performed on yeast grown on nitrocellulose-overlaid agar media. Positive pairs were picked by hand, re-arrayed and tested for the LacZ marker. Plate size for (A-C) was $125 \mathrm{~mm} \times 85 \mathrm{~mm}$.

arrayed Nub strains (1536-well format) on YPD plates. Twentyfour hours later, cells were transferred to DS media to select for diploid cells (a representative plate is shown in Figure 2A). After 3 days of growth at $28^{\circ} \mathrm{C}$, cells were pinned robotically to IS media. Three methionine levels, which regulate the MET25 promoter driving the Cub fusions, were used to vary the stringency of the screening conditions (Figure 2B). Putative interactors were identified by visual inspection, based on complementation of the His 3 marker (histidine auxotrophy) and the Ade2 marker (absence of red pigments). The interaction screen identified 386 pPPIs. One NubG clone, AT5G06100, a MYB transcription factor (consistent with being a "false positive" due to "auto-activation"; 86 interactors) was not included in further experiments. The remaining positive interaction pairs were re-arrayed and retested for complementation of his 3 , for red color of ade2 mutants and the third marker, LacZ. 88.9\% of the initial positive pairs (343 out of $386)$ showed a positive read-out for the all three markers (representative plate, Figure 2C). Pairs that showed a positive read-out for all three markers (Table S3 in Supplementary Material) were entered into Cytoscape 2.6.3 (Shannon et al., 2003) to visualize the network (Figure 3). Network analysis was performed using NetworkAnalyzer 2.6.1 (Assenov et al., 2008). The final network, AMPv2, consists of 179 proteins linked by 343 edges; the node degree distribution follows the power-law with $r^{2}=0.863$, indicating that the network is scale-free (Figure 4). From this network, a set of five subnets was selected covering RLKs (Figure 5), the seven-transmembrane domain receptors (7TM receptors; Figure 6), calcium and phosphoinositide related proteins (Figure 7), and an AMT ammonium transporter (Figure 8). Hundred and forty-one LRR-RLKs out of the 223 encoded by the genome and 8 MLOs (Mildew resistance locus o) out of 15 were represented in this screen. The pPPIs identified in this screen are discussed in more detail below.

\section{RECEPTOR-LIKE KINASE POTENTIALLY INTERACTING WITH THE AMMONIUM TRANSPORT AMT1}

The screen identified three RLKs (AT2G28990, AT1G72180, and AT5G59650) that gave a positive read-out with the ammonium transporter AMT1;1 or a mutant form of AMT1;1 (T460A; Figure 8A). Two of the AMT/RLK interactions found in AMPv2 screen were tested independently in Arabidopsis leaf protoplasts using a split luciferase system (Fujiwara et al., 1993; Kato et al., 2010). An interaction test between an R-SNARE (VAMP721) with a Qa-SNARE (SYP122) was used as a positive control (Figure 8B). The luciferase activity obtained from coexpression of SYP122 with PHT1;4 (Arabidopsis phosphate transporter AT2G38940 that does not appear to interact with SYP122) served as a negative control (Figure 8B). Coexpression of SYP122 with VAMP721 produced 45 -fold higher luciferase activity compared to coexpression of SYP122 with PHT1;4. Previous work had shown that AMT1 functions as an oligomer and that a specific interaction of the cytosolic C-terminus of each of the three subunits is required for transporter activity (Obrdlik et al., 2004; Loqué et al., 2007). The ability of AMT1;1 to oligomerize was confirmed here since coexpression of an AMT1;1-NLuc and a corresponding CLuc fusion reconstituted significant luciferase activity. The two RLKs (AT2G28990 and AT1G72180) were fused C-terminally with CLuc. An interaction test with AMT1;1-NLuc yielded significant reconstitution of luciferase activity relative to the negative control (Figure 8B). This result was confirmed in a reciprocal test of AMT1;1-CLuc with the RLKs as C-terminal NLuc fusions (Figure 8B). Three independent experiments yielded comparable results. Thus the 


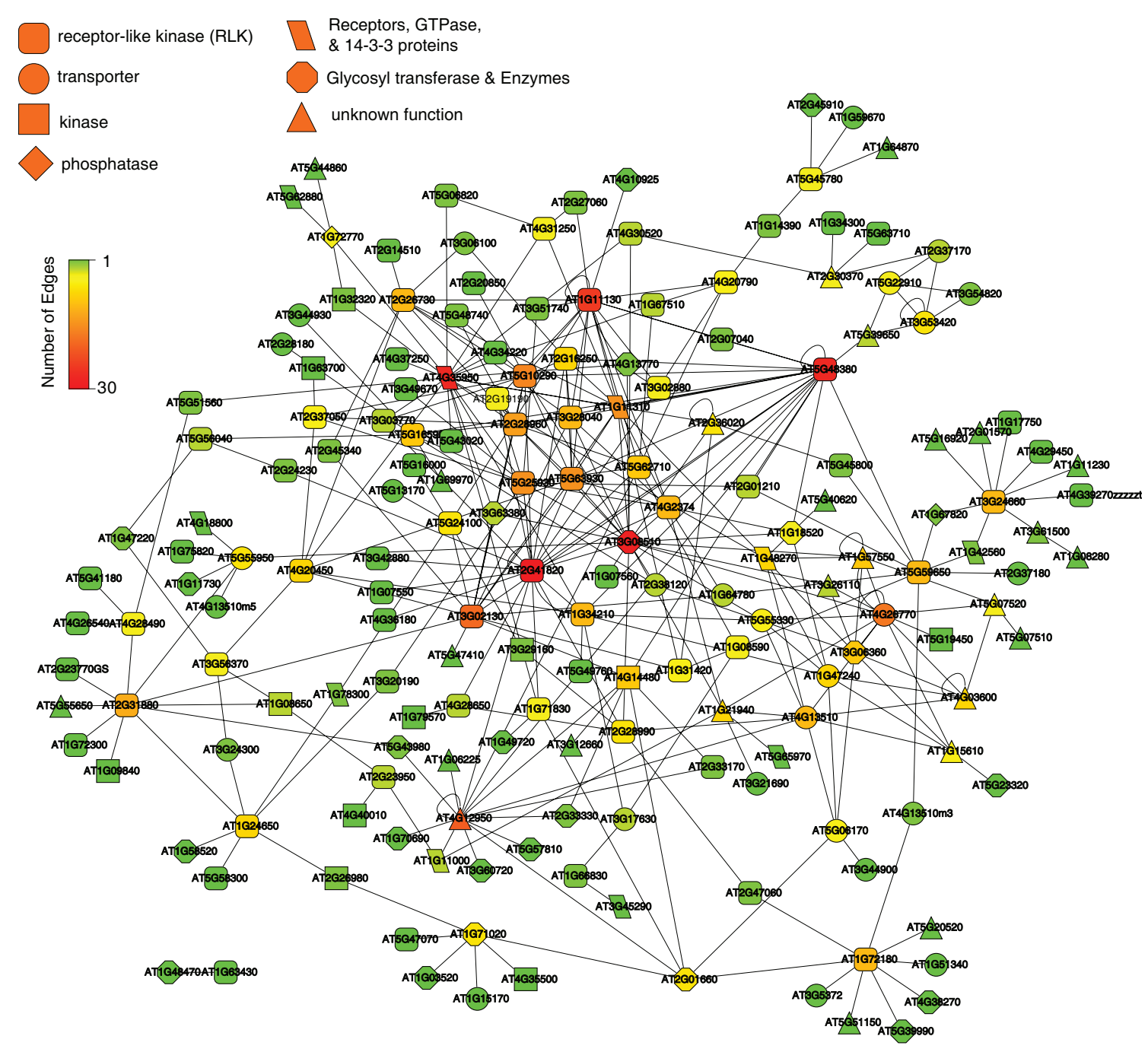

FIGURE 3 | AMPv2 pPPI network. Network of all pairs with a positive read-out for all three markers as visualized in Cytoscape. The network comprises 179 nodes and 343 edges. Symbol color corresponds to degree of interactions (color code on the left). Symbol shape indicates protein function (code at the top).

split luciferase system was able to confirm the interaction of AMTs with each other as well as a potential interaction of AMT1 with two RLKs.

\section{DISCUSSION}

Here we describe the cloning of 3,852 Arabidopsis ORFs and show the successful establishment of a high throughput membrane protein/signaling protein interaction screen using the mbSUS system in 1536-well format. To establish a high throughput screen for pPPIs, 490 ORFs were transferred into the yeast mbSUS vectors and used for an interaction screen (90,370 potential edges). A pre-screen aimed at putative "false positive" and "false negative" interactors eliminated $33.8 \%$ of the Cub fusions. Out of the remaining 59,805 potential PPIs between $443 \mathrm{Nub}$ fusions and $135 \mathrm{Cub}$ fusions, 343 pairs $(0.57 \%)$ were positive in the interaction screen. Surprisingly, despite the small number of actual interactions, given the total theoretical number of possible interactions among 490 ORFs, a network (AMPv2) with small world properties was identified.
LRR-RLKs are expected to play important roles in the plasticity of plant development and in interactions with the environment. Due to the large representation of LRR-RLKs here, this work may provide new leads for characterizing the physiological role of RLKs in plants. Interestingly, the ammonium transporter AMT1;1 gave reproducible interactions with three RLKs. Two RLKs (AT1G72180 and AT2G28990) were further tested and independently confirmed by the split luciferase assay in Arabidopsis leaf protoplasts, supporting the reliability of the observed pPPIs. The cloning of a large fraction of the plant membrane/signaling proteins as provided here, together with the successful establishment of this screening platform will provide the foundation for a genomic scale interaction study of protein-protein interactions. The present platform enables a throughput of approx 75,000 pPPIs to be tested per week and provides a basis for a systematic binary analysis of interactions between and among membrane and signaling proteins in a multicellular organism. 


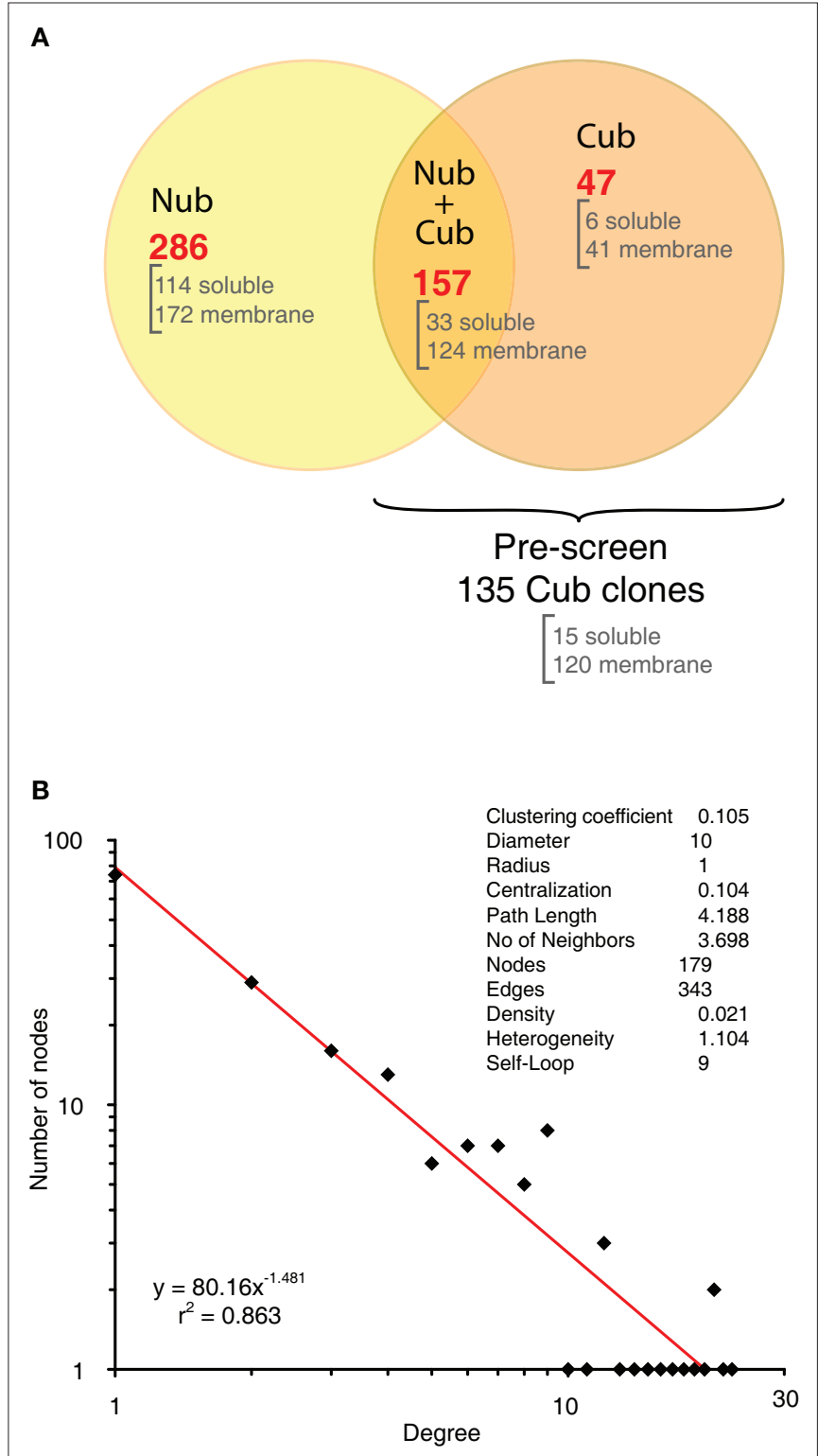

FIGURE 4 | Representation of Nub and Cub clones in AMPv2 network and frequency distribution of the resulting network. (A) The mbSUS screen was performed with 490 genes of which 443 were mobilized into the Nub destination vector and 204 into the Cub destination vector (157 genes were common to both pools). The pPPI network between 179 nodes yielded 343 edges. (B) The power law frequency distribution of the network was obtained with the "NetworkAnalysis" tool of Cytoscape.

\section{POTENTIAL AND LIMITATIONS OF THE LARGE-SCALE INTERACTOME SCREEN USING mbSUS}

As outlined in the introduction, a wide spectrum of studies support the reliability of the split ubiquitin system as a discovery tool for protein interactions. Nevertheless, the system is based on overexpression and thus may produce "false positive" results. Since yeast is a heterologous system, the plant proteins may either be targeted incorrectly, or accumulate in the endoplasmic reticulum (ER) or in carmellae (Villalba et al., 1992). The heterologous system can potentially lead to accumulation of proteins either at unphysiologically high levels or colocalization of proteins that localize to different compartments in the plant. This can lead to an increased probability of random collisions producing "false positive" read-outs (Dünnwald et al., 1999). Moreover, some interactions may require post-translational modifications, e.g., phosphorylation as a prerequisite for 14-3-3 binding, a modification that may be lacking in yeast. Our protocol eliminates "autoactivators" and proteins with insufficient expression levels in a pre-screen (cf. 3.3), providing a systematic source of "false negatives." A major advantage of large-scale screens will be that the data obtained are directly comparable, and that proteins with a propensity of giving "false positive" or "false negative" read-outs can be identified. The use of orthogonal interaction tests may be a means of testing the reliability of the mbSUS screens (Lalonde et al., 2008).

\section{INTERACTIONS WITH RECEPTOR-LIKE KINASES}

Membrane-localized RLKs recognize specific ligands via their $\mathrm{N}$-terminal extracytosolic domain and transmit ligand-binding status across the transmembrane domain to activate the intracellular kinase. Typically, intermolecular autophosphorylation within dimers leads to subsequent transduction of the signal to downstream targets (Pawson and Nash, 2000). Plant genomes are unique in that they contain $\sim 500$ genes encoding transmembrane RLKs (Arabidopsis 491, rice 807; Krupa et al., 2006). Plasma membranelocalized RLKs have been shown to function in development, as well as in hormone and defense signaling (De Smet et al., 2009; Tör et al., 2009; Zhao, 2009).

Although RLKs are thought to form heteromers, only a few protein-interactions of RLKs have been characterized in detail in plants. One of the best-characterized pairs is the brassinolide receptor BRI1 (AT4G39400) and its partner the BRI1-associated kinase BAK1 (AT4G33430). Both genes were present in our screen; however both were only tested as Nub fusions.

Here, the potential of 141 RLKs to interact with each other, or with other membrane and signaling proteins, was analyzed to gain insights into potential pathways in which these RLKs might be involved (e.g., RLKs potentially involved in regulating ammonium transporters; Figure 8). To analyze the pPPIs of RLKs in more detail, all nodes corresponding to RLKs were extracted from the network (Figure 5). The RLK sub-network comprises 80 RLKs forming 126 pPPIs. On average, RLKs share 3.0 edges with other proteins. The majority of RLKs (63) has four or fewer edges, whereas the LRR-RLK AT2G41820 had 21 edges (Figure 3). Three RLKs showed potential homo-oligomerization (AT5G48380, AT2G41820, and AT1G11130), 63 had heteromeric edges with other RLKs, and 13 RLKs potentially interacted exclusively with one other protein. Interestingly, 31 of the RLKs detected here had previously been found to be phosphorylated based on proteomics analyses (PhosPhAt 3.0; Durek et al., 2010), indicating that they might be substrates for the respective RLKs (blue dotted borders, Figure 5).

\section{INTERACTIONS WITH 7TM RECEPTORS}

The Arabidopsis genome encodes a single known Regulator of G-protein Signaling (RGS1, AT3G26090), single canonical G $\alpha$ and G $\beta$ subunits, and two G $\gamma$ subunits. The AMPv2 ORF set 


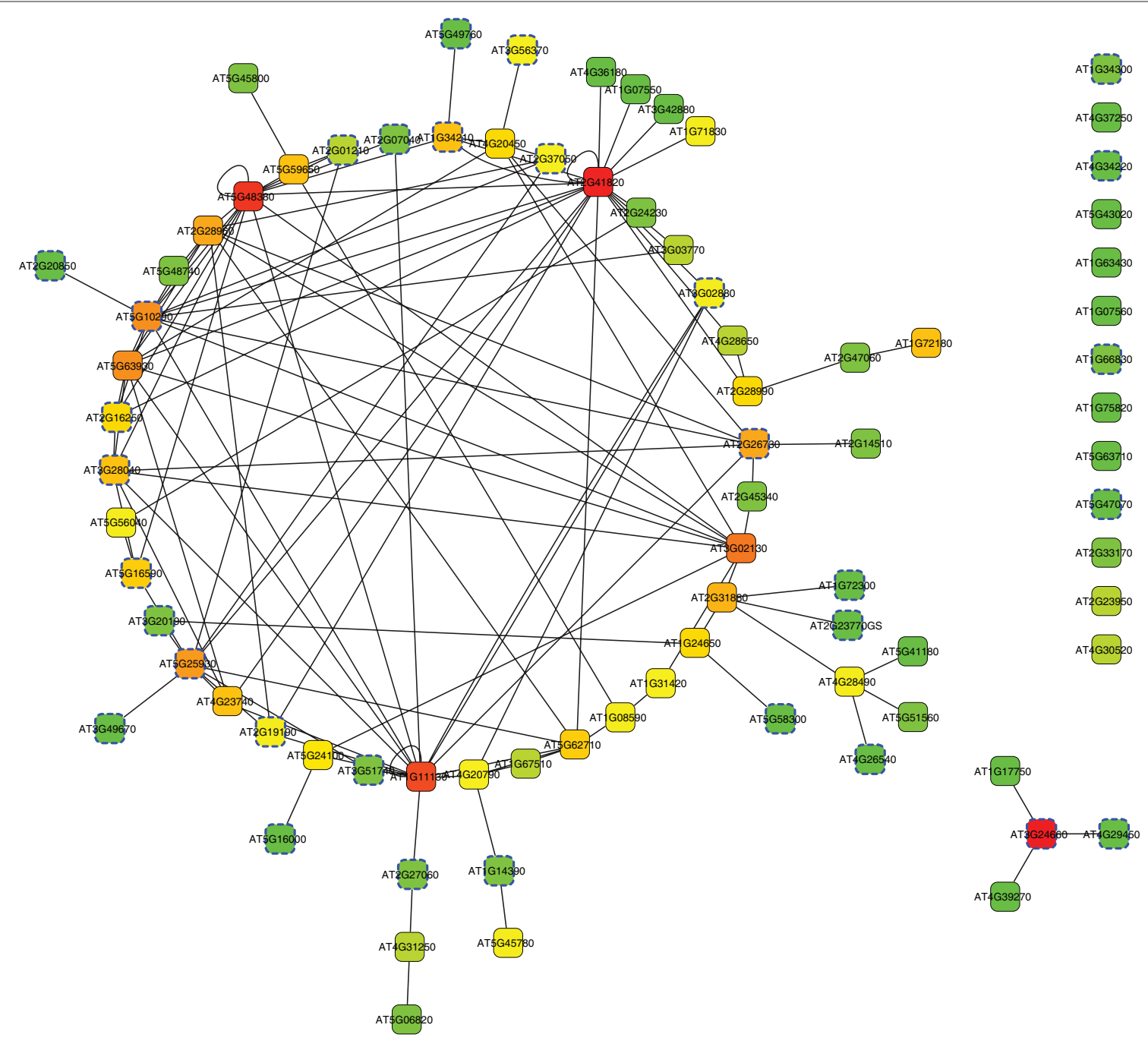

FIGURE 5 | Sub-network of receptor kinase interactions (RLK). Labeling as in Figure 3. The blue borders surrounding 31 individual RLKs indicate evidence for phosphorylated sites according to PhosPhAt 3.0 (Durek et al., 2010).

contained eighteen 7TM receptors: GCR1, which is a candidate G-protein-coupled receptor (GPCR) based on its sequence homology to Dictyostelium GPCRs, one "unknown," two transferases, six members of the MtN3 family, and eight MLO receptors (Devoto et al., 2003). Of these 18 genes, 8 were present in the network, including GCR1 and five MLOs (for the AGI number, see Figure 6). All MLO interactions and their first neighbors were extracted (Figure 6A). Most striking is the finding that most MLOs are highly connected and are part of the same sub-network. MLO proteins have seven transmembrane domains (Devoto et al., 1999), but despite the topology reminiscent of GPCRs, previous reports had not shown an interaction of MLOs with heterotrimeric G-proteins (Kim et al., 2002; Chen et al., 2009). Here we show that MLO2 (AT1G11310) potentially interacts with GCR1 (AT1G48260, Figure 6A). Very few direct targets of G-protein signaling have been identified in plants, and our screen provides additional candidate targets, because we also observe potential interactions of GCR1 with the small G protein ROP5 (AT4G35950), the cell wall arabinogalactan protein AGP27 (AT3G06360), and two transporters (NRAMP2, AT1G47240, and ammonium transporter AMT1;1, AT4G13510; Figure 6B). It is interesting that three of these interactors (MLO2, NRAMP2, and AMT1;1) are also interaction partners of GCR1 (Figure 6B), suggesting the potential formation of a G-protein signaling complex.

\section{CALCIUM AND PHOSPHOINOSITIDES}

The second messenger calcium plays a central role in signal transduction. Calcium is involved in hormonal signaling, stress response signaling, plant cell development and host-pathogen interactions (McAinsh and Pittman, 2009). Changes in cytoplasmic calcium are generated by calcium channels and pumps, which mediate import and efflux of calcium across the plasma membrane, and release or storage from/in internal stores such as the ER or the vacuole (Mäser et al., 2001; Kim et al., 2010). In Arabidopsis, autoinhibited calcium ATPases (ACA) are encoded by 14 genes, and ACA proteins have been found at the plasma membrane and the ER (Boursiac 


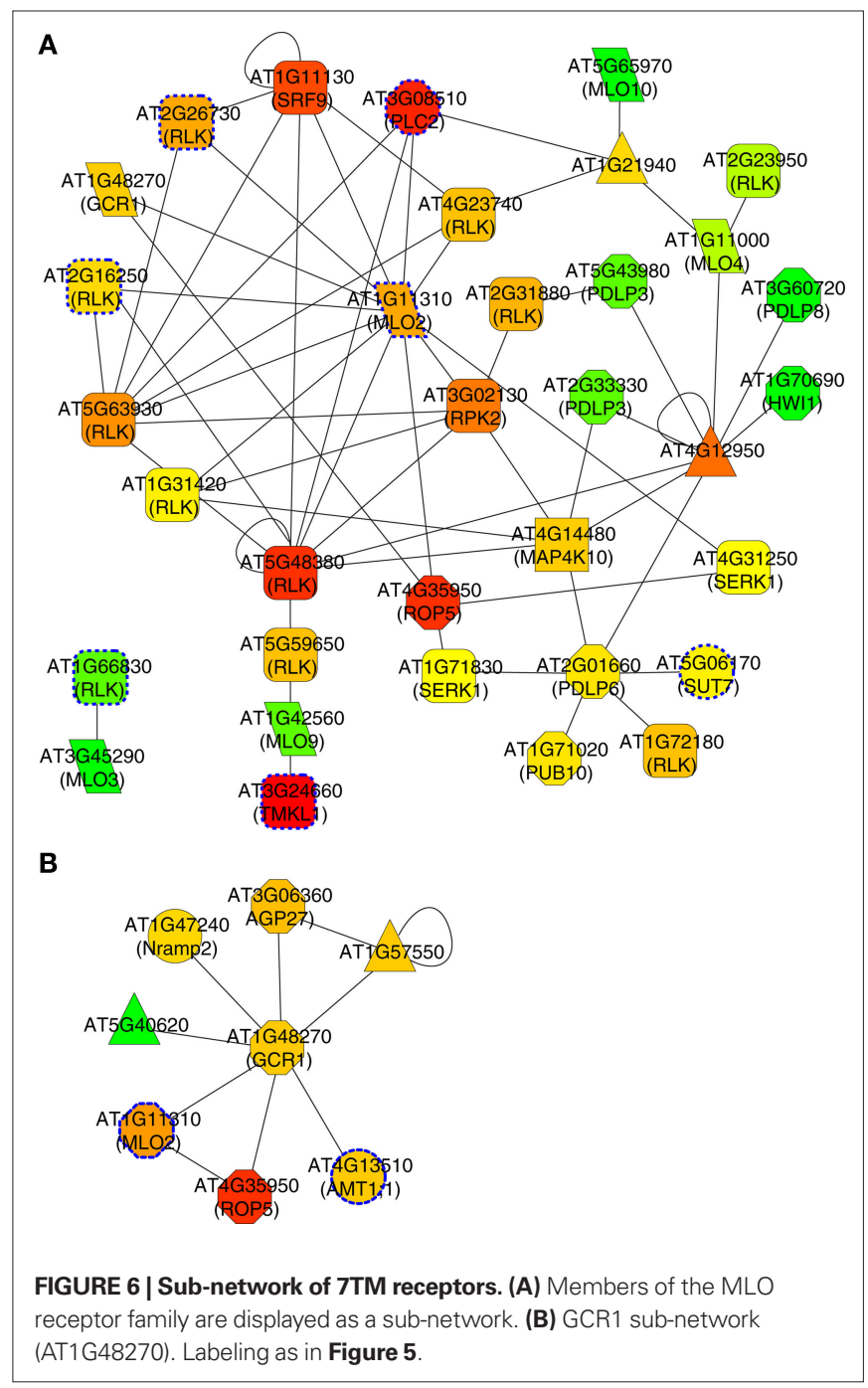

and Harper, 2007). The plasma membrane ACA12 (AT3G63380, Boursiac and Harper, 2007) showed putative interactions with the receptor-like kinase RPK2ITOAD2 (AT3G02130), ROP5 (AT4G35950), and phospholipase PLC2 (AT3G08510, Figure 7A). All four genes in this sub-network are expressed in open flowers (Schmid et al., 2005). Thus the observed interactions can occur in planta supporting a role in flower-related processes. PLC2, a phosphoinositide-specific phospholipase (PI-PLC) catalyzes the hydrolysis of phosphoinositide $\left[\mathrm{PI}(4,5) \mathrm{P}_{2}\right]$ to inositol trisphosphate $\left[\operatorname{Ins}(1,4,5) \mathrm{P}_{3}\right]$ and diacylglycerol (DAG), which function as second messengers. Ins $(1,4,5) \mathrm{P}_{3}$ and DAG are known to stimulate release of $\mathrm{Ca}^{2+}$ from intracellular stores and $\mathrm{Ca}^{2+}$ entry in many eukaryotic cells (Taylor, 2002). Arabidopsis encodes seven PI-PLCs; here only PLC2 (AT3G08510) was tested. PLC2 has the potential to interact with the $\mathrm{Ca}^{2+}$-ATPase ACA12, 10 RLKs, three transporters, four unknown proteins, MLO2, a tetraspanin, and with CDP-cytidine synthase (Figure 7B).

The putative interactions between a small GTPase (ROP), phospholipase (PLC), a calcium pump (ACA), and a RLK (Figure 7B) may be linked functionally because both calcium and phosphoinositides play important roles in polarized growth. Moreover, all four proteins probably localize to the plasma membrane. PLC2 activity maintains polarity of RAC-ROP signaling, thereby affecting actin organization and membrane traffic. RACROP signaling and Ins $(1,4,5) \mathrm{P}_{3}$ affect calcium, and calcium can affect PLC2. ACA12 appears to be the central connector of the four pPPIs. However it is important to note that not all possible binary interactions were tested. One may thus hypothesize that ACA12 can exist in a complex with the phosphoinositide metabolism enzymes and is involved in calcium flux across the plasma membrane. The interaction with the RLK RPK2ITOAD2 may function as a regulator of the participating enzyme activity, e.g., ACA12.

\section{AQUAPORIN INTERACTIONS}

In addition to a crucial role in signaling, the plasma membrane is key to uptake and efflux of water, ions and metabolites. Many transporters have been shown to exist as oligomers and interact with regulators (Loqué et al., 2007). To identify clusters of interacting proteins that might form a complex or co-functioning module, we clustered the network with the MCL algorithm (Enright et al., 2002), resulting in 27 clusters. We performed GO enrichment analyses on the clusters containing at least three genes against all genes in the network as background using Ontologizer (Bauer et al., 2008) and found only one cluster that was enriched in relation to water deprivation (cluster 17). This group comprises three aquaporins, one cation/ion exchanger (CHX9, AT5G22910), and one protein of unknown function (Figure 7C). The unknown protein is predicted to contain four transmembrane spanning domains and has a DUF679 motif (domain of unknown function 679). Aquaporins of PIP1 and PIP2 families are known to homo- and hetero-oligomerize (Zelazny et al., 2007). We find interactions between PIP2;2 (AT2G37170) and PIP2;1 (AT3G53420), and between PIP2;1 and PIP2;5 (AT3G54820), as well as homomerization of PIP2;1. No other homodimer of PIPs could have been found because only PIP2;1 was present in the screen as both a Cub and Nub fusion.

\section{AMMONIUM TRANSPORTER INTERACTIONS}

Plant ammonium transporters function as trimers. The activity of the three subunits in the complex is allosterically regulated via trans-activation by the cytosolic C-terminus (Loqué et al., 2007). An increase of the extracellular ammonium concentrations was shown to trigger phosphorylation of a critical threonine (T460) in the transactivation domain of the C-terminus (Loqué et al., 2007; Lanquar et al., 2009). Besides the regulatory site T460 in the C-terminus of AMT1;1 (AT4G13510), additional phosphorylation sites have been identified, suggesting that a suite of protein kinases regulates AMT activity (Lanquar et al., 2009). Because AMT1;1 phosphorylation is triggered by extracellular ammonium, RLKs might be prime candidate kinases involved in ammonium perception.

Here, AMT1;1 and a mutant form (T460A) were found to interact with three different RLKs (AT2G28990, AT1G72180, and AT5G59650) (Figure 8A). Two of the AMT/RLK interactions found in our mbSUS screen were tested independently in plant cells using a split luciferase system (Fujiwara et al., 1993; Kato et al., 2010). As may have been anticipated from the fact that AMTs oligomerize, 

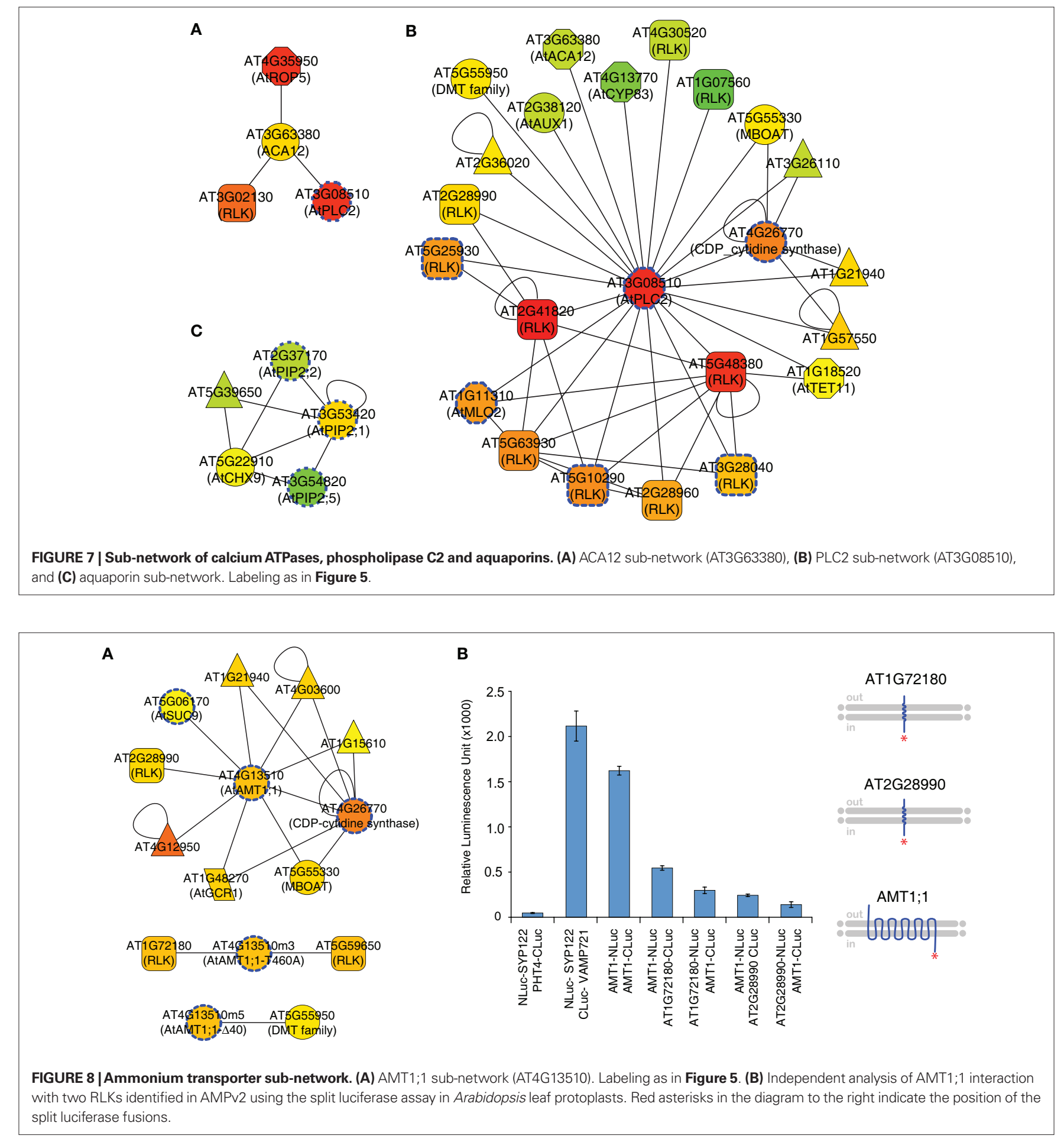

coexpression of an AMT1;1-NLuc and a CLuc fusion reconstituted significant luciferase activity, at a level similar to a positive control interaction of an R-SNARE (VAMP721) with a Qa-SNARE (SYP122). Coexpression of both RLKs fused C-terminally with CLuc (AT2G28990 and AT1G72180) with AMT1;1-NLuc yielded significant luciferase reconstitution relative to the negative control. This result was confirmed in a reciprocal test of AMT1;1-CLuc with the RLKs as C-terminal NLuc fusions. Further analyses will be required to determine whether AMT1 is a substrate for the RLKs, and if so, which residues in AMT1 are phosphorylated.

In addition to the RLK interactions, the AMPv2 screen suggested that AMT may interact with three other transporters, four "unknowns," and two signaling related proteins: GCR1 (AT1G48270) and CDP-cytidine synthase (Figure 8A). 


\section{COMPARISON OF AMPv2 TO SOLUBLE PROTEIN INTERACTION DATA SETS}

We did not find any of the pPPIs in the networks of Popescu et al. (2009), Intact (1,692 proteins and 3,424 interactions), BioGrid (release 62; 1,645 proteins and 3,291 interactions) or TAIR $(1,334$ proteins and 2,178 interactions; as of June 2010). This may not be surprising because only 83 out of the 490 ORFs (as Nub and/or $\mathrm{Cub}$ ) tested here were common to all the databases listed above. This difference may in part be due to the fact that AMPv2 focused on membrane and signaling proteins, whereas $89 \%$ of the ORFs in the above four databases are predicted to be soluble. The public databases contained eight putative interactions that could not be confirmed in this screen (Table 1). Furthermore, well-documented interactions such as between BRI1 and BAK1, BRI1 with the $14-3-3 \lambda$ protein were not tested because all three were only present as Nub fusions (Gampala et al., 2007; Schulze et al., 2010). Further work will be required to determine whether these represent "false negatives" in AMPv2.

\section{CONCLUSION}

Over 3,852 Gateway-compatible ORFs, encoding typically difficult to clone membrane protein genes, have been generated and made publicly available through ABRC. We have identified 343 potential protein-protein interactions among 179 proteins including 134 membrane proteins. Membrane protein and signaling protein interactions provide a basis for analyses into the physiological functions of plant membrane proteins. A larger scale screen, currently in progress, with a binary matrix using $>2,000$ proteins should reveal more information on the prevalence of "sticky" proteins and the overall topology of a membrane-based sub-interactome, and is expected to provide a wealth of leads for further biochemical, physiological, and bioinformatic analyses into plant membrane protein regulation and function.

\section{CONTRIBUTIONS}

Sylvie Lalonde, Wolf B. Frommer, Sarah M. Assmann, June M. Kwak, Seung Y. Rhee, Julian I. Schroeder conceived the study; Sylvie Lalonde and Wolf B. Frommer supervised the project and wrote the manuscript; Guillaume Pilot, Rainer Schwacke, and Réjane Pratelli generated the target list of candidates; Antoinette Sero, Réjane Pratelli, Guillaume Pilot, Maria I. Sardi, Saman A. Parsa, Do-Young Kim, Biswa R. Acharya, Erica V. Stein, Heng-Chen Hu, Florent Villiers, Kouji Takeda, Yong S. Han,

\section{REFERENCES}

Adams, A., Gottschling, D. E., Kaiser, C. A., and Stearns, T. (1998). Methods in Yeast Genetics. New York: Cold Spring Harbor Laboratory Press.

Assenov, Y., Ramirez, F., Schelhorn, S. E., Lengauer, T., and Albrecht, M. (2008). Computing topological parameters of biological networks. Bioinformatics 24, 282-284.

Bauer, S., Grossmann, S., Vingron, M., and Robinson, P. N. (2008). Ontologizer 2.0-a multifunctional tool for GO term enrichment analysis and data exploration. Bioinformatics 24, 1650-1651.
Bernsel, A., Viklund, H., Hennerdal, A., and Elofsson, A. (2009). TOPCONS: consensus prediction of membrane protein topology. Nucleic Acids Res. 37, W465-W468.

Boursiac, Y., and Harper, J. F. (2007). The origin and function of calmodulin regulated $\mathrm{Ca}^{2+}$ pumps in plants. $J$. Bioenerg. Biomembr. 39, 409-414.

Chen, Z., Noir, S., Kwaaitaal, M., Hartmann, H. A., Wu, M. J., Mudgil, Y., Sukumar, P., Muday, G., Panstruga, R., and Jones, A. M. (2009). Two seventransmembrane domain MILDEW RESISTANCE LOCUS O proteins

Table 1 | Published interactions (Popescu, Intact, BioGrid, orTAIR) that were not found in our screen.

AT4G33430 (BAK1|SERK3) = AT1G17750 (RLK/Pelle)

AT4G33430 (BAK1|SERK3) = AT5G48380 (BIR1)

AT1G34210 (SERK2) = AT1G34210 (SERK2)

AT1G75820 (CLV1) = AT1G65380 (CLV2)

AT3G02520 (14-3-3 Nu) = AT1G71830 (SERK1)

AT4G39400 (Bri1|Bin1) = AT1G71830 (SERK1)

AT5G10450 (14-3-3 lambda) = AT1G71830 (SERK1)

AT1G75820 (CLV1) = AT1G75820 (CLV1)

Yingzhen Yang generated the ORF/mbSUS clones, Antoinette Sero, Do-Young Kim, Maria I. Sardi, and Saman A. Parsa carried out the mbSUS screen; Sylvie Lalonde, Rainer Schwacke, Jin Chen, and Seung Y. Rhee performed the bioinformatics analyses, William Chiang and Naohiro Kato carried out the split luciferase assays; and Dominique Loqué established the 96-well yeast transformation.

\section{ACKNOWLEDGMENTS}

We thank the following researchers for donating clones: Joe Ecker (Salk Institute), Steven Clouse (NCSU), John M. Ward (University of Minnesota), Heven Sze (University of Maryland), Alan Jones (UNC), Gary Stacey (University of Missouri-Columbia), Henrik Vibe Scheller (JBEI/LBNL), Sébastien Thomine (CNRS Gif-surYvette), Christophe Maurel (CNRS Montpellier), Klaus Harter (University of Tübingen), Ralph Panstruga (MPI for Plant Breeding Research), Jirí Friml (Ghent University), Markus Klein (Universität Zürich), Enrico Martinoia (Universität Zürich), and many others (please see www.associomics.org). We thank the ABRC stock center for distribution of the vectors and clones. We thank Angela Lam (Carnegie), William Monsell (Penn State), Aaron P. Smith (LSU), and Elena Batista (LSU) for excellent technical assistance. This work was made possible by an NSF Arabidopsis 2010 grant (MCB-0618402) to Wolf B. Frommer, Sarah M. Assmann, June M. Kwak, Seung Y. Rhee, and Julian I. Schroeder.

\section{SUPPLEMENTARY MATERIAL}

The Supplementary Material for this article can be found online at http://www.frontiersin.org/physiology/plantphysiology/ paper/10.3389/fphys.2010.00024/

cofunction in Arabidopsis root thigmomorphogenesis. Plant Cell 21, 1972-1991.

De Smet, I., Voss, U., Jürgens, G., and Beeckman, T. (2009). Receptor-like kinases shape the plant. Nat. Cell Biol. 11, 1166-1173.

Devoto, A., Piffanelli, P., Nilsson, I., Wallin, E., Panstruga, R., von Heijne, G., and Schulze-Lefert, P. (1999). Topology, subcellular localization, and sequence diversity of the Mlo family in plants. J. Biol. Chem. 274, 34993-35004.

Devoto, A., Hartmann, H. A., Piffanelli, P., Elliott, C., Simmons, C., Taramino, G.,
Goh, C. S., Cohen, F. E., Emerson, B. C., Schulze-Lefert, P., and Panstruga, R. (2003). Molecular phylogeny and evolution of the plant-specific seventransmembrane MLO family. J. Mol. Evol. 56, 77-88.

Downing, W. L., Mauxion, F., Fauvarque, M. O., Reviron, M. P., Devienne, D., Vartanian, N., and Giraudat, J. (1992). A Brassica napus transcript encoding a protein related to the Kunitz protease inhibitor family accumulates upon water-stress in leaves, not in seeds. Plant J. 2, 685-693. 
Dünnwald, M., Varshavsky, A., and Johnsson, N. (1999). Detection of transient in vivo interactions between substrate and transporter during protein translocation into the endoplasmic reticulum. Mol. Biol. Cell 10, 329-344.

Durek, P., Schmidt, R., Heazlewood, J. L., Jones, A., MacLean, D., Nagel, A., Kersten, B., and Schulze, W. X. (2010). PhosPhAt: the Arabidopsis thaliana phosphorylation site database. An update. Nucleic Acids Res. 38, D828-D834.

Egana, L. A., Cuevas, R. A., Baust, T. B., Parra, L. A., Leak, R. K., Hochendoner, S., Pena, K., Quiroz, M., Hong, W. C., Dorostkar, M. M., Janz, R., Sitte, H. H., and Torres, G. E. (2009). Physical and functional interaction between the dopamine transporter and the synaptic vesicle protein synaptogyrin-3. J. Neurosci. 29, 4592-4604.

Enright, A. J., van Dongen, S., and Ouzounis, C. A. (2002). An efficient algorithm for large-scale detection of protein families. Nucleic Acids Res. 30, 1575-1584.

Fujikawa, Y., and Kato, N. (2007). Split luciferase complementation assay to study protein-protein interactions in Arabidopsis protoplasts. Plant J. 52, 185-195.

Fujiwara, T., Giesman-Cookmeyer, D., Ding, B., Lommel, S. A., and Lucas, W. J. (1993). Cell-to-cell trafficking of macromolecules through plasmodesmata potentiated by the red clover necrotic mosaic virus movement protein. Plant Cell 5, 1783-1794.

Gampala, S. S., Kim, T. W., He, J. X., Tang, W. Q., Deng, Z. P., Bai, M. Y., Guan, S. H., Lalonde, S., Sun, Y., Gendron, J. M., Chen, H. J., Shibagaki, N., Ferl, R. J., Ehrhardt, D., Chong, K., Burlingame, A. L., and Wang, Z. Y. (2007). An essential role for 14-3-3 proteins in brassinosteroid signal transduction in Arabidopsis. Dev. Cell 13, 177-189.

Geisler-Lee, J., O’Toole, N., Ammar, R., Provart, N. J., Millar, A. H., and Geisler, M. (2007). A predicted interactome for Arabidopsis. Plant Physiol. 145, 317-329.

Gietz, R. D., and Woods, R. A. (2002). Transformation of yeast by the LiAc/ SS carrier DNA/PEG method. Methods Enzymol. 350, 87-96.

Gisler, S. M., Kittanakom, S., Fuster, D., Wong, V., Bertic, M., Radanovic, T., Hall, R. A., Murer, H., Biber, J., Markovich, D., Moe, O.W., and Stagljar, I. (2008). Monitoring protein-protein interactions between the mammalian integral membrane transporters and PDZ-interacting partners using a modified split-ubiquitin membrane yeast two-hybrid system. Mol. Cell. Proteomics 7, 1362-1377.
Grefen, C., Stadele, K., Ruzicka, K. Obrdlik, P., Harter, K., and Horak, J. (2008). Subcellular localization and in vivo interactions of the Arabidopsis thaliana ethylene receptor family members. Mol. Plant 1, 308-320.

Johnsson, N., and Varshavsky, A. (1994). Split ubiquitin as a sensor of protein interactions in vivo. Proc. Natl. Acad. Sci. U.S.A. 91, 10340-10344.

Kall, L., Krogh, A., and Sonnhammer, E. L. (2007). Advantages of combined transmembrane topology and signal peptide prediction - the Phobius web server. Nucleic Acids Res. 35, W429-W432.

Kato, N., and Jonse, J. (2010). "The split luciferase complementation assay," in Plant Developmental Biology, eds L. Hennig and C. Köhler (New York: Springer), 359-376.

Kato, N., Fujikawa, Y., Fuselier, T., Adamou-Dodo, R., Nishitani, A., and Sato, M. H. (2010). Luminescence detection of SNARE-SNARE interaction in Arabidopsis protoplasts. Plant Mol. Biol. 72, 433-444.

Kim, M.C., Panstruga, R., Elliott, C., Muller, J., Devoto, A., Yoon, H. W., Park, H. C. Cho, M. J., and Schulze-Lefert, P. (2002). Calmodulin interacts with MLO protein to regulate defence against mildew in barley. Nature 416, 447-451.

Kim, T.-H., Bohmer, M., Hu, H., Nishimura, N., and Schroeder, J. I. (2010). Guard cell signal transduction network: advances in understanding abscisic acid, $\mathrm{CO}_{2}$, and $\mathrm{Ca}^{2+}$ signaling. Annu. Rev. Plant Biol. 61, 561-591.

Krogh, A., Larsson, B., von Heijne, G., and Sonnhammer, E. L. (2001). Predicting transmembrane protein topology with a hidden Markov model: application to complete genomes. J.Mol. Biol.305, 567-580.

Krupa, A., Anamika, K., and Srinivasan, N. (2006). Genome-wide comparative analyses of domain organisation of repertoires of protein kinases of Arabidopsis thaliana and Oryza sativa. Gene 380, 1-13.

Lalonde, S., Ehrhardt, D. W., Loque, D., Chen, J., Rhee, S. Y., and Frommer, W. B. (2008). Molecular and cellular approaches for the detection of protein-protein interactions: latest techniques and current limitations. Plant J. 53, 610-635.

Lanquar, V., Loqué, D., Hörmann, F., Yuan, L., Bohner, A., Engelsberger, W. R., Lalonde, S., Schulze, W. X., von Wirén, N., and Frommer, W. B. (2009). Feedback inhibition of ammonium uptake by a phospho-dependent allosteric mechanism in Arabidopsis. Plant Cell 21, 3610-3622.

Lanquar, V., and Frommer, W. B. (2010). Adjusting ammonium uptake via phosphorylation. Plant Signal. Behav. 5. (in press)

Loqué, D., Lalonde, S., Looger, L., von Wirén, N., and Frommer, W. (2007). Trans-activation and cooperativity in an ammonium transporter complex. Nature 446, 195-198.

Masalkar,P., Wallace, I.S.,Hwang, J.H., and Roberts, D. M. (2010). Interaction of cytosolic glutamine synthetase of soybean root nodules with the $\mathrm{C}$-terminal domain of the symbiosome membrane nodulin 26 aquaglyceroporin. J. Biol. Chem. 285, 23880-23888.

Mäser, P., Thomine, S., Schroeder, J. I., Ward, J. M., Hirschi, K., Sze, H., Talke, I. N., Amtmann, A., Maathuis, F. J., Sanders, D., Harper, J. F., Tchieu, J., Gribskov, M., Persans, M. W., Salt, D. E., Kim, S. A., and Guerinot, M. L. (2001). Phylogenetic relationships within cation transporter families of Arabidopsis. Plant Physiol. 126, 1646-1667.

McAinsh, M. R., and Pittman, J. K. (2009). Shaping the calcium signature. New Phytol. 181, 275-294.

Miller, J. P., Lo, R. S., Ben-Hur, A. Desmarais, C., Stagljar, I., Noble, W.S. and Fields, S. (2005). Large-scale identification of yeast integral membrane protein interactions. Proc. Natl. Acad. Sci. U.S.A. 102, 12123-12128.

Obrdlik, P.,El-Bakkoury, M.,Hamacher, T., Cappellaro, C., Vilarino, C., Fleischer, C., Ellerbrok, H., Kamuzinzi, R., Ledent, V., Blaudez, D., Sanders, D., Revuelta, J. L., Boles, E., Andre, B., and Frommer, W. B. (2004). $\mathrm{K}^{+}$channel interactions detected by a genetic system optimized for systematic studies of membrane protein interactions. Proc. Natl. Acad. Sci. U.S.A. 101, 12242-12247.

Pawson, T., and Nash, P. (2000). Proteinprotein interactions define specificity in signal transduction. Genes Dev. 14, 1027-1047.

Popescu, S. C., Popescu, G. V., Bachan, S., Zhang, Z., Gerstein, M., Snyder, M., and Dinesh-Kumar, S. P. (2009). MAPK target networks in Arabidopsis thaliana revealed using functional protein microarrays. Genes Dev. 23, 80-92.

Rahim, G., Bischof, S., Kessler, F., and Agne, B. (2009). In vivo interaction between atToc33 and atToc159 GTPbinding domains demonstrated in a plant split-ubiquitin system. J. Exp. Bot. 60, 257-267.

Rand, K. (1996). Crystal violet can be used to visualize DNA bands during gel electrophoresis and to improve cloning efficiency. Tech. Tips Online 1, 23-24.

Rozen, S., and Skaletsky, H. (2000). Primer3 on the WWW for general users and for biologist programmers. Methods Mol. Biol. 132, 365-386.
Rual, J. F., Venkatesan, K., Hao, T. Hirozane-Kishikawa, T., Dricot, A., Li, N., Berriz, G. F., Gibbons, F. D. Dreze, M., Ayivi-Guedehoussou, N., Klitgord, N., Simon, C., Boxem, M., Milstein, S., Rosenberg, J., Goldberg, D. S., Zhang, L. V., Wong, S. L., Franklin, G., Li, S. M., Albala, J. S., Lim, J. H., Fraughton, C., Llamosas, E., Cevik, S., Bex, C., Lamesch, P., Sikorski, R. S., Vandenhaute, J., Zoghbi, H. Y., Smolyar, A., Bosak, S., Sequerra, R., Doucette-Stamm, L., Cusick, M. E., Hill, D. E., Roth, F. P., and Vidal, M. (2005). Towards a proteome-scale map of the human protein-protein interaction network. Nature 437, 1173-1178.

Schmid, M., Davison, T. S., Henz, S R., Pape, U. J., Demar, M., Vingron, M., Scholkopf, B., Weigel, D., and Lohmann, J. U. (2005). A gene expression map of Arabidopsis thatiana development. Nat. Genet. 37, 501-506.

Schulze, B., Mentzel, T., Jehle, A. K., Mueller, K., Beeler, S., Boller, T., Felix, G., and Chinchilla, D. (2010). Rapid heteromerization and phosphorylation of ligand-activated plant transmembrane receptors and their associated kinase BAK1. J. Biol. Chem. 285, 9444-9451.

Schulze, W., Reinders, A., Ward, J. M., Lalonde, S., and Frommer, W. B. (2003). Interactions between co-expressed Arabidopsis sucrose transporters in the split-ubiquitin system. $B M C$ Biochem. 4, 3.

Schwacke, R., Schneider, A., van der Graaff, E., Fischer, K., Catoni, E., Desimone, M., Frommer, W. B., Flügge, U.-I., and Kunze, R. (2003). ARAMEMNON, a novel database for Arabidopsis integral membrane proteins. Plant Physiol. 131, 16-26.

Shannon, P., Markiel, A., Ozier, O., Baliga, N. S., Wang, J. T., Ramage, D., Amin, N., Schwikowski, B., and Ideker, T. (2003). Cytoscape: a software environment for integrated models of biomolecular interaction networks. Genome Res. 13, 2498-2504.

Simonis, N., Rual, J. F., Carvunis, A. R., Tasan, M., Lemmens, I., HirozaneKishikawa, T., Hao, T., Sahalie, J. M., Venkatesan, K., Gebreab, F., Cevik, S., Klitgord, N., Fan, C., Braun, P., Li, N., Ayivi-Guedehoussou, N., Dann, E., Bertin, N., Szeto, D., Dricot, A., Yildirim, M. A., Lin, C., de Smet, A. S., Kao, H.L., Simon, C., Smolyar,A.,Ahn, J. S., Tewari, M., Boxem, M., Milstein, S., Yu, H., Dreze, M., Vandenhaute, J., Gunsalus, K. C., Cusick, M. E., Hill, D. E., Tavernier, J., Roth, F. P., and Vidal, M. (2009). Empirically controlled mapping of the Caenorhabditis elegans 
protein-protein interactome network. Nat. Methods 6, 47-54.

Taylor, C. W. (2002). Controlling calcium entry. Cell 111, 767-769.

Tör, M., Lotze, M. T., and Holton, N. (2009). Receptor-mediated signalling in plants: molecular patterns and programmes. J. Exp. Bot. 60, 3645-3654.

Underwood, B. A., Vanderhaeghen, R., Whitford, R., Town, C. D., and Hilson, P. (2006).Simultaneous high-throughput recombinational cloning of open reading frames in closed and open configurations. Plant Biotechnol. J. 4, 317-324.

Venkatesan, K., Rual, J. F., Vazquez, A., Stelzl, U., Lemmens, I., HirozaneKishikawa, T., Hao, T., Zenkner, M., Xin, X., Goh, K. I., Yildirim, M. A., Simonis, N., Heinzmann, K., Gebreab, F., Sahalie, J. M., Cevik, S., Simon, C., de Smet, A. S., Dann, E., Smolyar, A., Vinayagam, A., Yu, H., Szeto, D., Borick, H., Dricot, A., Klitgord, N., Murray, R. R., Lin, C., Lalowski, M., Timm, J., Rau, K., Boone, C., Braun, P., Cusick, M. E., Roth, F. P., Hill, D. E.,
Tavernier, J., Wanker, E. E., Barabasi, A. L., and Vidal, M. (2009). An empirical framework for binary interactome mapping. Nat. Methods 6, 83-90.

Villalba, J.M., Palmgren, M. G., Berberian, G. E., Ferguson, C., and Serrano, R. (1992). Functional expression of plant plasma membrane $\mathrm{H}^{+}$-ATPase in yeast endoplasmic reticulum. J. Biol. Chem. 267, 12341-12349.

Yu, H., Braun, P., Yildirim, M. A., Lemmens, I., Venkatesan, K., Sahalie, J., Hirozane-Kishikawa, T., Gebreab, F., Li, N., Simonis, N., Hao, T., Rual, J. F., Dricot, A., Vazquez, A., Murray, R. R., Simon, C., Tardivo, L., Tam, S., Svrzikapa, N., Fan, C., de Smet, A. S., Motyl, A., Hudson, M. E., Park, J., Xin, X., Cusick, M. E., Moore, T., Boone, C., Snyder, M., Roth, F. P., Barabasi, A. L., Tavernier, J., Hill, D. E., and Vidal, M. (2008). High-quality binary protein interaction map of the yeast interactome network. Science 322, 104-110.

Zelazny, E., Borst, J. W., Muylaert, M., Batoko, H., Hemminga, M. A., and
Chaumont, F. (2007). FRET imaging in living maize cells reveals that plasma membrane aquaporins interact to regulate their subcellular localization. Proc. Natl. Acad. Sci. U.S.A. 104, 12359-12364.

Zhao, D. Z. (2009). Control of anther cell differentiation: a teamwork of receptor-like kinases. Sex. Plant Reprod. 22, 221-228.

Zhao, J., Connorton, J. M., Guo, Y., Li, X., Shigaki, T., Hirschi, K. D., and Pittman, J. K. (2009). Functional studies of split Arabidopsis $\mathrm{Ca}^{2+} / \mathrm{H}^{+}$exchangers. J. Biol. Chem. 284, 34075-34083.

Conflict of Interest Statement: The authors declare that the research was conducted in the absence of any commercial or financial relationships that could be construed as a potential conflict of interest.

Received: 11 June 2010; paper pending published: 04 July 2010; accepted: 20 July 2010; published online: 22 September 2010.
Citation: Lalonde S, Sero A, Pratelli R, Pilot G, Chen J, Sardi MI, Parsa SA, Kim D-Y, Acharya BR, Stein EV, Hu H-C, Villiers F, Takeda K, Yang Y, Han YS, Schwacke R, Chiang W, Kato N, Loqué D, Assmann SM, Kwak JM, Schroeder JI, Rhee SY and Frommer WB (2010) A membrane protein/signaling protein interaction network for Arabidopsis version AMPv2. Front. Physio. 1:24. doi: 10.3389/fphys.2010.00024

This article was submitted to Frontiers in Plant Physiology, a specialty of Frontiers in Physiology

Copyright (C) 2010 Lalonde, Sero, Pratelli, Pilot, Chen, Sardi, Parsa, Kim, Acharya, Stein, Hu, Villiers, Takeda, Yang, Han, Schwacke, Chiang, Kato, Loqué, Assmann, Kwak, Schroeder, Rhee and Frommer. This is an open-access article subject to an exclusive license agreement between the authors and the Frontiers Research Foundation, which permits unrestricted use, distribution, and reproduction in any medium, provided the original authors and source are credited. 